\title{
Life cycle cost and economic assessment of biochar-based bioenergy production and biochar land application in Northwestern Ontario, Canada
}

\author{
Krish Homagain $^{1 *}$ (D, Chander Shahi ${ }^{1}$, Nancy Luckai ${ }^{1}$ and Mahadev Sharma ${ }^{2}$
}

\begin{abstract}
Background: Replacement of fossil fuel based energy with biochar-based bioenergy production can help reduce greenhouse gas emissions while mitigating the adverse impacts of climate change and global warming. However, the production of biochar-based bioenergy depends on a sustainable supply of biomass. Although, Northwestern Ontario has a rich and sustainable supply of woody biomass, a comprehensive life cycle cost and economic assessment of biochar-based bioenergy production technology has not been done so far in the region.

Methods: In this paper, we conducted a thorough life cycle cost assessment (LCCA) of biochar-based bioenergy production and its land application under four different scenarios: 1) biochar production with low feedstock availability; 2) biochar production with high feedstock availability; 3 ) biochar production with low feedstock availability and its land application; and 4) biochar production with high feedstock availability and its land application- using SimaPro ${ }^{\oplus}$, EIOLCA ${ }^{\oplus}$ software and spreadsheet modeling. Based on the LCCA results, we further conducted an economic assessment for the break-even and viability of this technology over the project period.

Results: It was found that the economic viability of biochar-based bioenergy production system within the life cycle analysis system boundary based on study assumptions is directly dependent on costs of pyrolysis, feedstock processing (drying, grinding and pelletization) and collection on site and the value of total carbon offset provided by the system. Sensitivity analysis of transportation distance and different values of $C$ offset showed that the system is profitable in case of high biomass availability within $200 \mathrm{~km}$ and when the cost of carbon sequestration exceeds CAD $\$ 60$ per tonne of equivalent carbon $\left(\mathrm{CO}_{2} \mathrm{e}\right)$.

Conclusions: Biochar-based bioenergy system is economically viable when life cycle costs and environmental assumptions are accounted for. This study provides a medium scale slow-pyrolysis plant scenario and we recommend similar experiments with large-scale plants in order to implement the technology at industrial scale.
\end{abstract}

Keywords: LCA, LCCA, SimaPro, Biochar, Biomass, Pyrolysis, Bioenergy, Wood Pellets

\footnotetext{
*Correspondence: khomagai@lakeheadu.ca

${ }^{1}$ Faculty of Natural Resources Management, Lakehead University, 955 Oliver

Rd., Thunder Bay, ON P7B 5E1, Canada

Full list of author information is available at the end of the article
} 


\section{Background}

Biochar ${ }^{1}$-based bioenergy production through slow pyrolysis ${ }^{2}$ of sustainably produced biomass feedstock is one of the simplest and cheapest method among several carbon capture and storage (CCS) methods (Woolf et al. 2010). Production of biochar and bioenergy is gaining significant momentum worldwide over the last decade with a steady growth of $3 \%$ per year (IEA 2015; IBI 2016). Growing worldwide attention towards combating the adverse impacts of climate change, and the future courses of actions towards climate related issues were willfully agreed during the recent (2015) climate conference in Paris by different nations. Canada made a further commitment to achieve $30 \%$ reduction in $\mathrm{CO}_{2}$ from 2005 levels by 2030 which basically lies within the provincial jurisdictions as management of natural resources is a provincial affair in Canada. The Province of Ontario further targeted to reduce $37 \% \mathrm{CO}_{2}$ from 1990 levels by 2030 (Lyman 2015; MOECC 2015). As a forest resource rich province, Ontario has the best opportunity to utilize its forest-based biomass to reduce carbon emission by reducing its dependency towards much debated fossil fuel. A significant step towards this has already begun in Ontario as the province legally banned coal burning for the power generation.

Use of biomass-based feedstocks especially from agriculture and forestry has been popular in recent years. Northwestern Ontario (NWO), in particular, has a rich and sustainable source of woody biomass supply through the sustainable management of about 12 million ha of productive forest through 18 Forest Management Plans (MNRF 2015). Several previous studies (Wood and Layzell 2003; Hacatoglu et al. 2011; Kennedy et al 2011; Alam et al. 2012) have also indicated that the NWO forests are capable of sustainably supplying enough biomass feedstock to generate electricity from power-generating stations, which used coal as feedstock until 2014. One of the limiting factors in the use of biomass feedstock for power generation is the energy density and its vast variability within different types of woody biomass. To overcome this limitation and to continue a sustained supply of the feedstock, the wood biomass raw materials are being processed and pelletized. Atikokan generating station (AGS-200 MW) in NWO, a coal burning power plant recently converted to wood burning facility has already started using locally produced wood pellets to produce clean electricity. Although the production of bioenergy ${ }^{3}$ is a fairly established technology, it is not economically competitive compared to the production of energy using fossil fuel, because of its high cost of production (Klinar 2016). The other secondary issue related to bioenergy production that is gaining momentum is landfilling with wood ash, which may contain heavy metals. If these issues are not properly addressed, bioenergy production may lose its competitive edge as a clean energy producing technology. Co-production of biochar with bioenergy, and applying biochar back to the land from where the biomass feedstock originated is suggested as one of the most feasible solutions for GHG emissions and waste management issues (Lehmann and Joseph 2009). Several life cycle analysis studies including our study (Homagain et al. 2015) have shown GHG emissions reduction with co-production (Winsley 2007; Roberts et al. 2010; McElligott et al. 2011; Sohi 2013). However, there is no study to our knowledge, which conducts a comprehensive life cycle cost assessment of the biocharbased bioenergy system, and accounts for every step of the production and use cycle.

Most of the related studies in literature focus on economic assessment of biochar systems (McCarl et al. 2009; Pratt and Moran 2010; Roberts et al. 2010; Galinato et al. 2011; Shackley et al. 2011; Yoder et al. 2011). These studies typically found that the potential economic profitability of biochar production systems varies depending on the feedstock used (Roberts et al. 2010; Cleary et al. 2015), the conversion technology employed (Pratt and Moran 2010; Bruun et al. 2011), or the inclusion of carbon sequestration subsidies or carbon credits $^{14}$ reflecting the social value of GHG mitigation (Pratt and Moran 2010; Roberts et al. 2010; Galinato et al. 2011; Shackley et al. 2011). One study, modeling the trade-off between product yield and product quality as conversion temperature increases, has explored the implications of different production techniques and resulting variations in biochar properties for overall system performance (Yoder et al. 2011). Recent technoeconomic assessments of slow-pyrolysis biochar and heat production (Klinar 2016; Patel et al. 2016) also showed that the biochar system can be profitable provided it is customized into the local production system. The size and scale of the biochar system affects the cost and its economic viability. Studies that compared the life cycle costs of different scale bioenergy systems with (Kulyk 2012) and without (Roberts et al. 2010; Cleary et al. 2015) biochar land application found that production cost of large-scale plant is lower than smaller scale plant but the GHG mitigation cost for large-scale plant is very high as compared to the smaller plant. For the purpose of this paper, we define 'biochar-based bioenergy' as the energy (char, syngas and bio-oil) produced by slow pyrolysis of woody biomass in a pyrolysis plant in the absence of oxygen. Bio-oil and syngas are then converted into electricity and biochar is applied in the same forest land where the raw material was collected. In this paper we assess the life cycle cost of producing biochar-based bioenergy and its land application with high and low availability scenario of biomass feedstock in NWO, Canada. 


\section{Methods}

Life cycle cost analysis is a combination of life cycle environmental assessment, life cycle costing and economic analysis. We used a combination of LCA outputs, collected cost information for each analysis steps and scenario, created LCCA spreadsheet calculation tool, calculated net present value for each analysis scenario and conducted break-even analysis.

LCCA system boundary, study area and analysis scenarios Life cycle cost analysis system boundary is presented in Fig. 1. This is the same study area and system boundary that was used in life cycle assessment of biochar based bioenergy in our earlier paper (Homagain et al. 2015). The system boundary extends from raw material collection to the application of biochar to the forest including the co-products to the market, and covers different interdependent phases including collection, transportation, storage, processing and pyrolysis.

The study area lies in NWO Canada, where the Atikokan Generating Station (AGS) has been converted from coal to biomass (wood pellet) feedstock (OPG 2012). NWO has a vast amount of forest based woody biomass which can sustainably supply biomass feedstock to recently converted powerplant. Although AGS plans to use the combustion process for energy generation, our study uses different scenarios where biomass feedstock is converted into bio-oil, syngas and biochar using the normally available slowpyrolysis machine in order to illustrate the cost assessment of biochar-based bioenergy production. The input-output data for the system boundary and unit processes were obtained directly from published literature, the NWO regional forest management units, forest management plans, and personal communications with harvesters, transporters and other professionals.

Our hypothetical biochar system is a medium sized (1 MWh) slow-pyrolysis system with fixed bed twin-fire pyrolyzer (Power Max 2015) with a life span of 25 years. We used four different cost analysis scenarios based on the availability of biomass feedstock, transportation distance and application of biochar back to the same forest land from where it was collected. Basic description of these scenarios is provided in Table 1.

Same average transportation distance $(300 \mathrm{~km}$ for low availability and $100 \mathrm{~km}$ for high availability) for biochar land application is used as feedstock transportation. Biochar land application rate is used as 50 tonne per ha which was set during the life cycle assessment in $\mathrm{SimaPro}^{\circledR}$ assumption (See Homagain et al. 2015 for details).

\section{Life cycle costing and net present value}

Following the life cycle environmental assessment (Homagain et al. 2015), we conducted a comprehensive life cycle cost assessment of each production stage within the system boundary using the following model (Eq. 1). Description of each variable and the sources of information are given in Table 2.

$$
L C C_{t}=M S C_{t}+F C C_{t}+T C_{t}+S P C_{t}+P C_{t}+L A C_{t}
$$

where $L C C_{t}=$ total life cycle cost at year $t, M S C_{t}=$

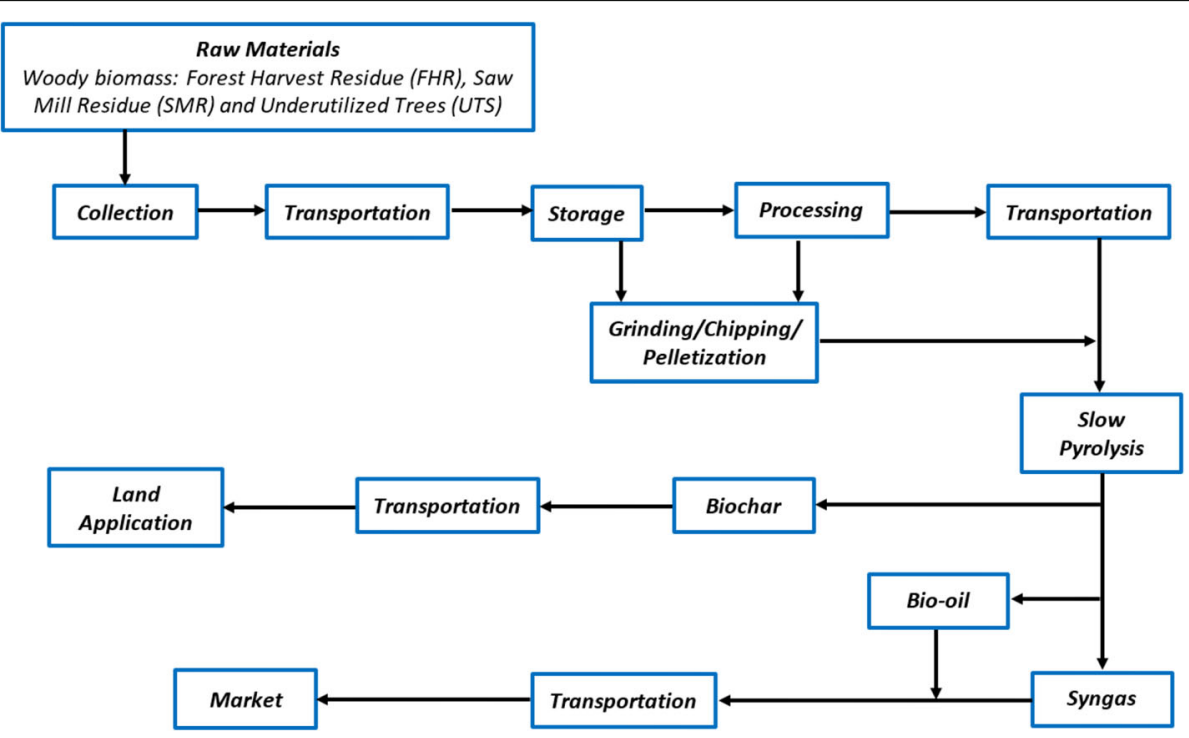

Fig. 1 System boundary for LCCA of biochar-based bioenergy production 
Table 1 Life cycle cost assessment scenarios

\begin{tabular}{lllll}
\hline Scenario & Feedstock availability & Feedstock transportation distance $(\mathrm{km})$ & Biochar land application & Project period (year) \\
\hline 1. Biochar Low & Low & More than 200 & No & 25 \\
& & Average 300 & No & 25 \\
2. Biochar High & High & Less than 200 & & 25 \\
& & Average 100 & Yes & $50 \mathrm{t} \cdot \mathrm{ha}^{-1}$ at $300 \mathrm{~km}$ \\
3. Land Application Low & Low & More than 200 & Yes & 25 \\
4. Land Application High & High & Average 300 & $50 \mathrm{t} \cdot \mathrm{ha}^{-1}$ at $100 \mathrm{~km}$
\end{tabular}

machine and setup cost at year $t, F C C_{t}=$ feedstock collection cost at year $t, T C_{t}=$ transportation cost at year $t$, $S P C_{t}=$ storage/processing cost at year $t, P C_{t}=$ pyrolysis cost at year $t$, and $L A C_{t}=$ land application cost at year $t$.

We used SimaPro $^{\circledR}$ for life cycle assessment (Pre Consultants 2013) and Environmental Input and Output Life Cycle Assessment $\left(\mathrm{EIOLCA}^{\oplus}\right)$ for detailed cost assessment (GDI 2010). We then developed a spreadsheet LCCA tool and calculated the whole life cycle cost of every stage of production. Revenue calculation included the equivalent electricity generated per $\mathrm{kWh}$ basis, and using the current market value for electricity, syngas and bio-oil. For non-land application scenarios (Scenarios 1 and 2), the by-product biochar was again used as fuel in the system. Carbon sequestration benefit (carbon credit) is also considered for land application scenarios. Similar transportation distance is assumed for market and land application of biochar as for feedstock transportation to processing site. A standard net present value model (Eq. 2) is used for the 15 year project period to calculate the NPV.

$$
N P V_{y}=\sum_{t=1}^{y}\left(R_{t}-C_{t}\right) /(1+r)^{t}
$$

where $N P V=$ net present value, $R=$ revenue, $C=$ life cycle cost, $r=$ discount rate. Discount rate is a factor that takes into account the effect of time value of money. It is defined as the financial advantage of one investment when compared to a risk free annual rate of return (EPA

Table 2 Description of specific cost information

\begin{tabular}{|c|c|c|}
\hline Variable & Description & Source \\
\hline Total life cycle cost (LCC) & $L C C_{t}=M S C_{t}+F C C_{t}+T C_{t}+S P C_{t}+P C_{t}+L A C_{t}$ & This study \\
\hline Machine and Setup Cost (MSC) & $\begin{array}{l}\text { - Planning-Feasibility study } \\
\text { - Environmental Impact Assessment (EIA) and development services } \\
\text { - Detailed Engineering Design } \\
\text { - Industry renewal fee } \\
\text { - Plant site Construction costs and maintenance in every } 5 \text { years. } \\
\text { - Equipment base price and delivery } \\
\text { - Plant Set Up and maintenance }\end{array}$ & MOECC 2015; PowerMax 2015, Pers. Comm. \\
\hline Feedstock Collection Cost (FCC) & $\begin{array}{l}\text { - Forest Harvest Residue (FHR) } \\
\text { - FHR-Labor-and related } \\
\text { - Saw Mill Residue (SMR) } \\
\text { - SMR-Labor- and related } \\
\text { - Underutilized trees (UTS) } \\
\text { - UTS-Labor- and related }\end{array}$ & $\begin{array}{l}\text { AAFC 2008; Gautam et al. 2010, Pers. Comm. } \\
\text { with harvesters; Upadhyay et al. } 2012\end{array}$ \\
\hline Transportation Cost (TC) & $\begin{array}{l}\text { - Feedstock Transportation to Storage } \\
\text { - Transportation from storage to Pyrolysis Facility } \\
\text { - Biochar Transportation to Land } \\
\text { - Bio-oil Syngas Transportation to market }\end{array}$ & AAFC 2008; Alam et al. 2012, Pers. Comm. \\
\hline Storage/Processing Cost (SPC) & $\begin{array}{l}\text { - Storage } \\
\text { - Grinding/Pelletization Cost }\end{array}$ & AAFC 2008; WPAC 2013, Pers. Comm. \\
\hline Pyrolysis Cost (PC) & $\begin{array}{l}\text { - Cost of plant operation } \\
\text { - Skilled labour/ Product Testing } \\
\text { - Pyrolyzed Products storage }\end{array}$ & NREL 2010; IRENA 2012 \\
\hline Land Application Cost (LAC) & $\begin{array}{l}\text { - Material handling, tractor and fuel costs } \\
\text { - Transportation and skilled labour costs } \\
\text { - Other incidental cost ( } 2 \%)\end{array}$ & Pers. Comm. with independent applicators \\
\hline
\end{tabular}


2010). Discount rate takes care of both the existing interest rate and inflation rate.

In general, the discount rate is calculated as: $r=i+f$, where $r$ is discount rate (nominal), $i$ is interest rate, and $f$ is inflation rate. The exact equation that links nominal and real interest rates is represented in (Eq. 3):

$$
(1+r)=(1+i)(1+f)
$$

Ten year averages of real interest and inflation rates were used (Bank of Canada 2013). Year 2013 is considered the base year for the project for all four scenarios, defined in Table 1, and all future costs and revenues are discounted for this year. Value of carbon sequestration is considered as one of the important dependent variable for the net present value calculation of the system. We also conducted a sensitivity analysis of different values of carbon credit and used CAD 60 for each equivalent tonne of carbon sequestered, while biochar is applied to the soil.

\section{Results}

Life cycle cost assessment tool (spreadsheets) with all assumptions and calculations are compiled in the Additional file 1. A 25 year average annual cost inventory of the biochar-based bioenergy system of $1 \mathrm{MWh}$ plant (Fig. 2) shows that cost of pyrolysis $\left(\$ 381,536\right.$ years $\left.^{-1}\right)$ is the most expensive stage of production followed by storage/processing $\left(\$ 237,171\right.$ year $^{-1}$ ) which includes pelletization. There is an extra cost of $\$ 156,739$ years $^{-1}$ and $\$$ 133,228 years $^{-1}$ for the land application of biochar for low and high availability of feedstock. Feedstock collection costs about \$ 134,053 years ${ }^{-1}$ (low availability) and \$ 113,945 years $^{-1}$ (high availability). Transportation costs for low and high availability are \$ 97,962 years ${ }^{-1}$ and \$ 83,268 years $^{-1}$, respectively. Pyrolyzer machine purchase, delivery, setup and environmental assessment costs as a whole averages $\$ 82,727$ years $^{-1}$.

Total inventory cost is further aggregated to calculate total annual cost of plant operation and its present value for each scenario and is presented in Fig. 3. Total annual plant operation cost is high in land application with low feedstock availability (Scenario 3) followed by land application with high feedstock availability (Scenario 4), biochar with low feedstock availability (Scenario 1), and biochar with high feedstock availability (Scenario 2). Average annual cost of operation from all scenarios is $\$$ 988,550 with a present value of $\$ 532,816$ in 2013 dollar terms and a discount rate of $5.06 \%$. A cumulative cost for all the scenarios (Fig. 4) shows that both land application scenarios cost more than 25 million.

Sensitivity analysis of carbon credit provided for each tonne equivalent of $\mathrm{CO}_{2}$ sequestration on rate of return of all four scenarios shows that both land application scenarios are profitable, but both biochar only scenarios are not profitable (Fig. 5). The rate of return maximizes at $9 \%$ when per tonne of carbon is priced at CAD 60. This figure is used for entire calculation and economic assessment.

We conducted a break-even analysis on the basis of 25 year revenue and cost at $\$ 60$ per tonne of $\mathrm{CO}_{2} \mathrm{e}$. The analysis is presented in Fig. 6 . It shows that scenario 4 (Land Application High) reaches into the break-even at about 12 years which has a return on investment (ROI) of $9 \%$. Similarly scenario 3 (Land Application Low) reaches break-even after 13 years with a ROI of $5 \%$. Scenario 2 (Biochar High) and scenario 1 (Biochar Low) reach break-even after 17 years with a negative ROI of $4 \%$ and $-6 \%$, respectively.

\section{Discussion}

Biochar based bioenergy production is a costly investment. Our LCCA analysis shows that it warrants at least about a million dollar investment each year for a 25 year

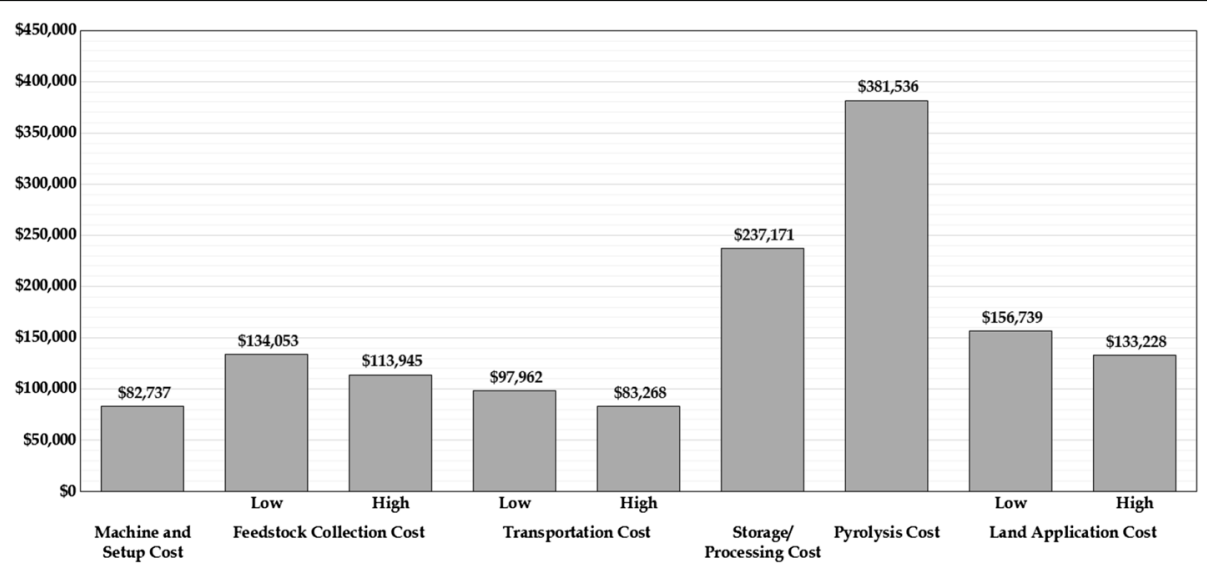

Fig. 2 Average annual life cycle cost inventory (undiscounted) for the biochar-based bioenergy system 


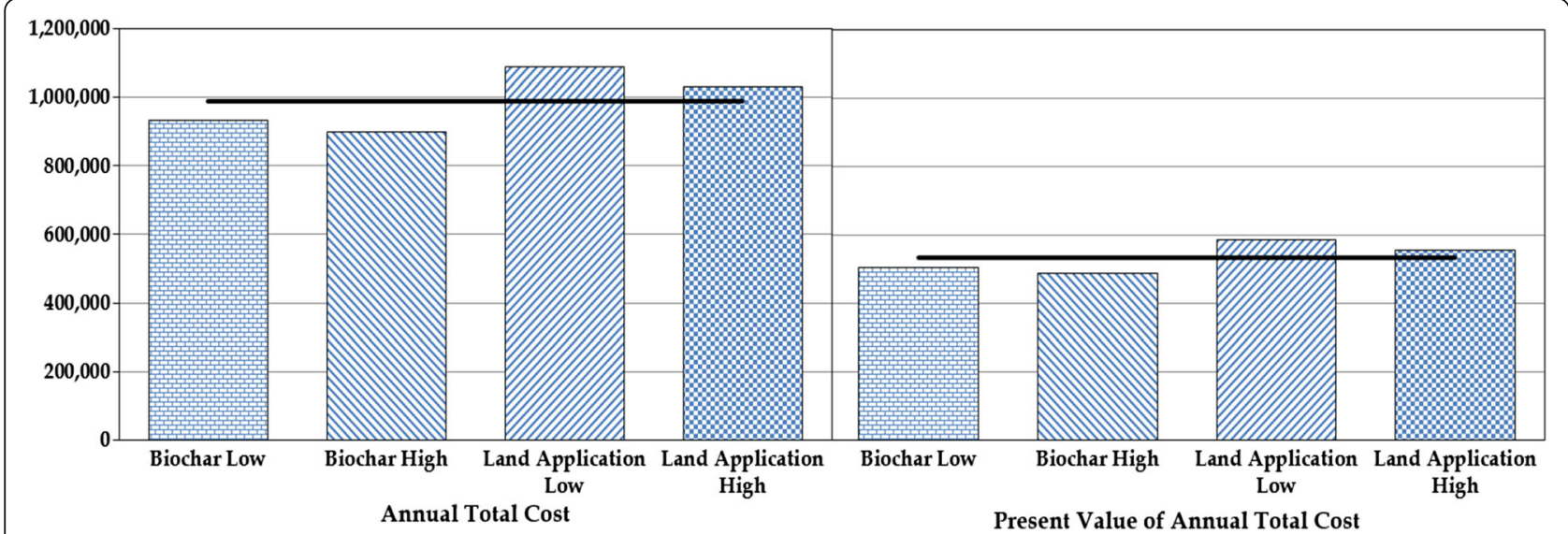

Fig. 3 Total annual (undiscounted) and present value (discounted) of biochar-based bioenergy production costs (\$) in different scenarios. (Horizontal solid line depicts the average)

project. However, we noticed some thoughtful observation in our results.

\section{Pyrolysis has the highest (36\%) share of total cost} Pyrolysis is the most costly stage among all production stages in the life cycle of bioenergy production and accounts for $36 \%$ of the total cost of the system. Although pyrolysis is an old and established technology, there is a need to develop highly efficient and optimized machines. When producing biochar, bio-oil and syngas, the pyrolyzer consumes large amounts of energy and requires more skilled work force as compared to other stages. The average annual cost for the 1-MWh pyrolyzer in our study is slightly more than a similar half-capacity portable pyrolyzer (Coleman et al. 2010), but is cheaper than bio-oil pyrolysis system used in the UK (Rogers and Brammer 2012).

In a study on carbon market investment criteria for biochar projects conducted by California Energy Commission (CEC 2014), the authors also found that pyrolysis may be one of the most energy/resource expensive investments for biochar production. Although, pyrolysis biochar is becoming popular, it is still in research and development stage. If the demand for bioenergy production increases due to its environmental benefits, there will be more emphasis on developing highly efficient and cost effective system, thereby reducing the cost of pyrolysis.

\section{Feedstock collection cost (12\%) is higher than transportation cost (9\%)}

Our study uses three types of feedstock: forest harvest residue, saw mill residue and underutilized trees that are available in the study area of NWO. Collection of these materials would be a relatively new business and there are no established companies that can provide a sustainable supply of feedstock. On the other hand, there is an established forestry raw material transportation service provided by contractors on a competitive basis in the study area. Collection of these vast amounts of scattered feedstock is relatively labour and time intensive, and

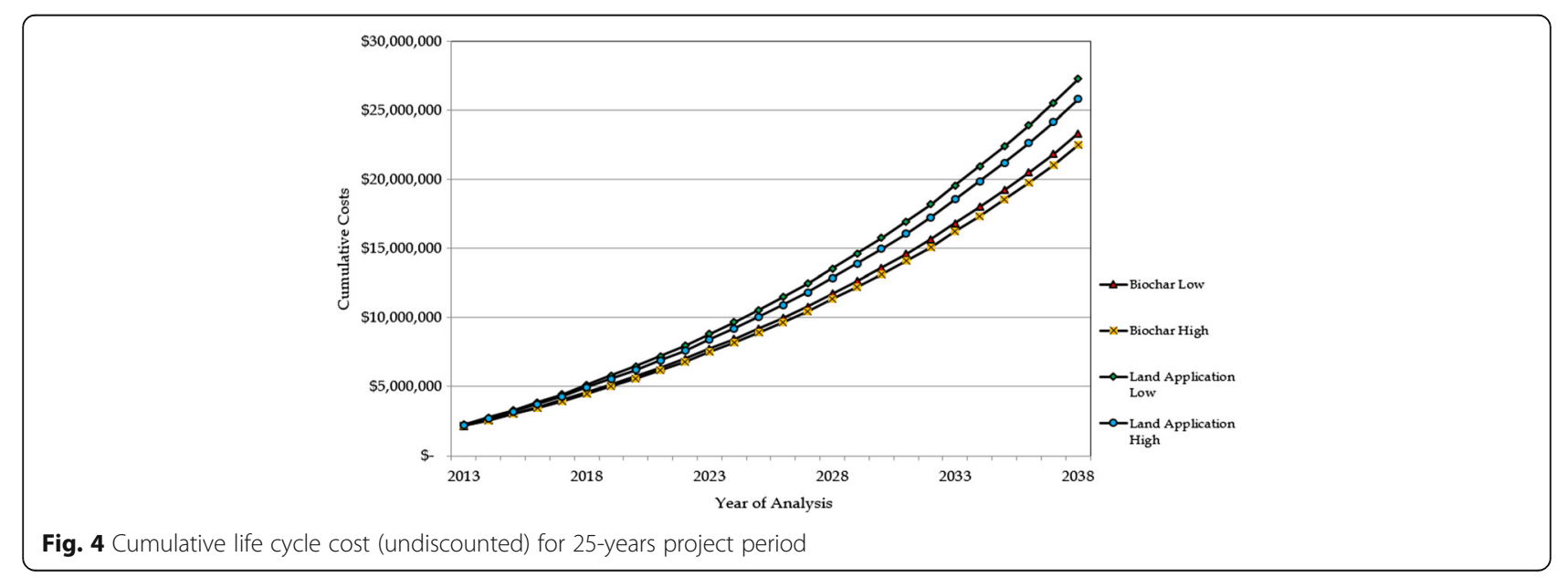




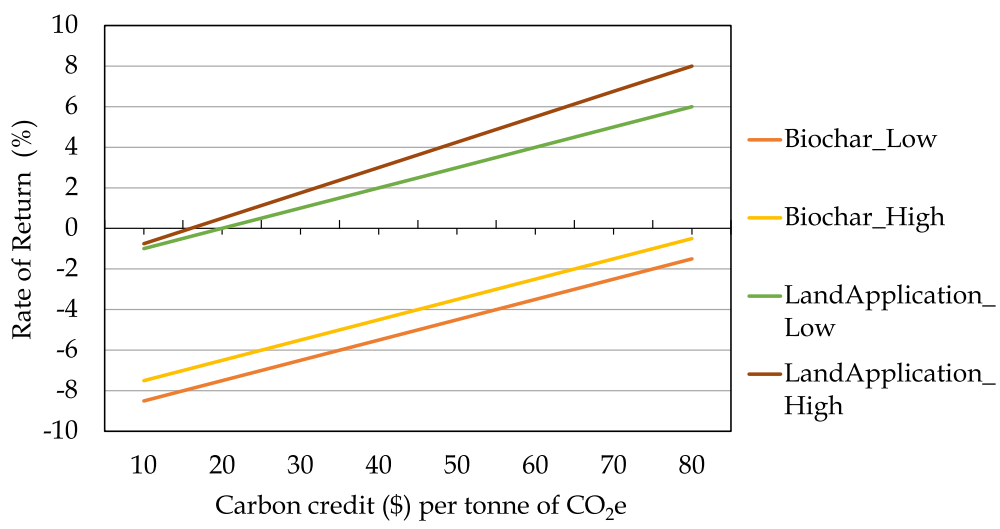

Fig. 5 Sensitivity of rate of return of a 25-years biochar based bioenergy system based on carbon credits

costs more than transportation. However, in other studies (Simon et al. 2010; Zhang 2010; Kung et al. 2013; Ronsse et al. 2013; Kaliyan et al. 2015) where the feedstock was mainly agriculture or municipal waste, the transportation cost was always found to be more than raw material collection cost.

\section{Land application cost (14\%) is higher than feedstock collection and transportation cost $(9 \%)$}

Biochar land application would be completely new business in the area. Land application in forest lands or in recently harvested area is a cumbersome job as compared to homogenous agriculture farming field. Our study used a rate of $50 \mathrm{t} \cdot \mathrm{ha}^{-1}$ which is almost half of what is suggested in the cropping field (Major 2010). Land variability, distance and rate of application may have contributed to the high cost of land application. However, land application is considered as paying carbon back to the nature for a long-term sequestration so the carbon credit accrued from the sequestration ultimately offsets this cost in the long run.

\section{Land application scenarios have early break even and more return}

Both land application scenarios with high and low feedstock availability have early break even periods (12 and 13 years) as compared to non-land application scenarios where break-even is after 17 years. This is because of the

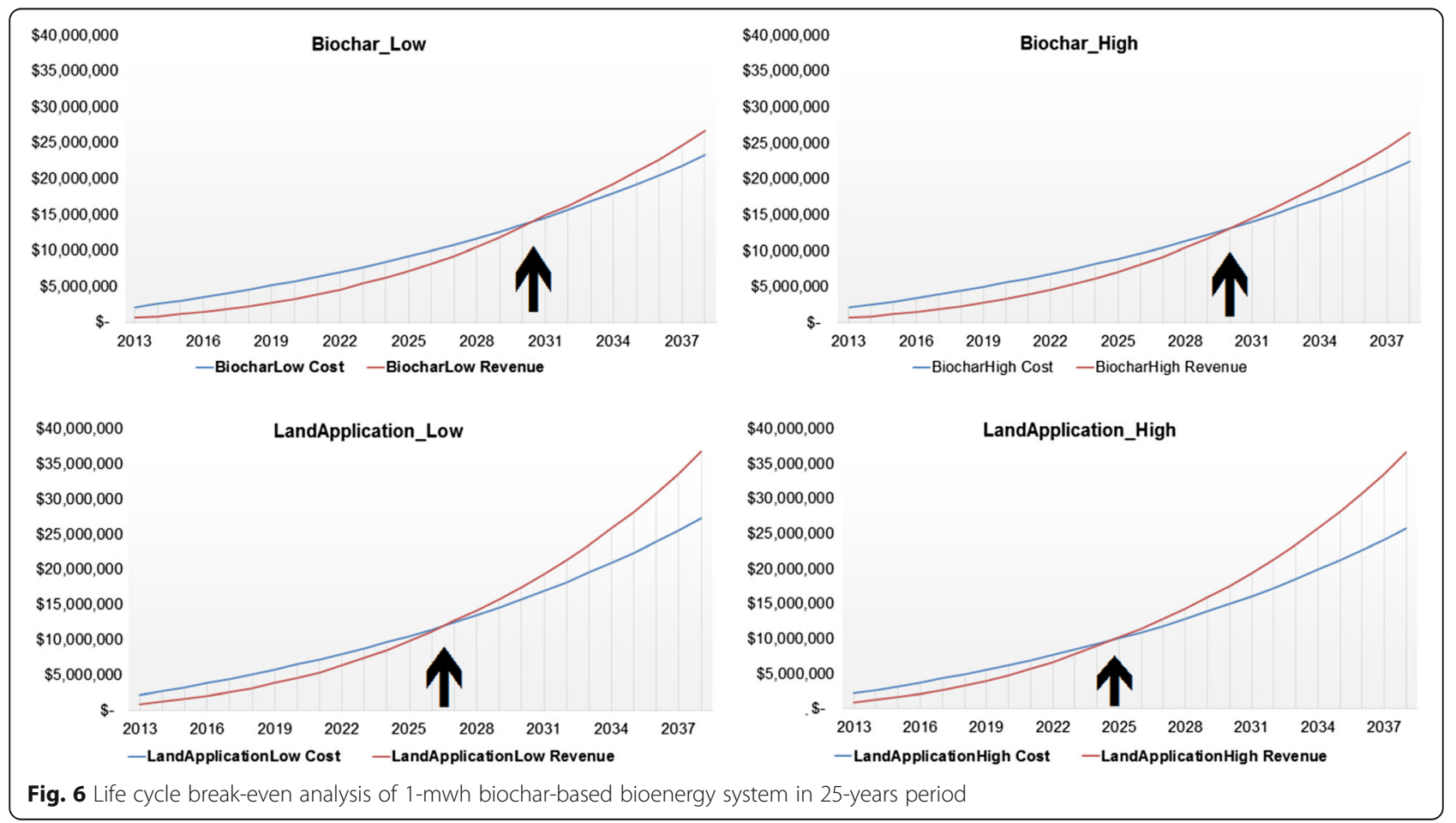


revenue generated through the carbon credits earned through the land application of biochar and the cost associated with the application is low as compared to the cost of land application.

\section{Limitation of the study}

Biochar-based bioenergy is a new socio-economic intervention in the area where fossil fuel has been contributing in the past. Social dimensions of bioenergy system especially macro-economic demand and supply side effects cannot be ignored while evaluating life cycle carbon and costs of the individual projects. This study did not consider this area, nor it did anything on the local job creation scenarios (direct, indirect and induces) as there are highly visible displacement effects and local job creation functions of the biochar-based bioenergy system.

This study was conducted during 2011-2013 (3 year span) when most of the wood market was relatively slow and energy prices (especially petroleum) were high as compared to 2014 onwards. Collection of cost information in a longitudinally spanned time frame may have caused some deviations in the total costs but all the future values are discounted with national real and 10 -year average inflation rates.

All other related costs above and beyond the system boundary (Fig. 1) is assumed to be constant throughout all study period and across all scenarios.

\section{Conclusions}

Canada has committed to achieving $30 \%$ reduction in $\mathrm{CO}_{2}$ emissions from 2005 levels by 2030, while the province of Ontario in Canada has further committed to reducing $\mathrm{CO}_{2}$ emissions by 37 \% from 1990 levels by 2030 . As a result, Ontario has banned the use of coal and is utilizing its forest-based biomass instead for energy production. However, the slow pyrolysis process of biocharbased bioenergy production has not been tested so far in Ontario due to its uncertain environmental and economic impacts. In this study we conducted a comprehensive life cycle cost and economic assessment analysis of biochar-based bioenergy production and biochar land application in Northwestern Ontario, Canada using LCA assumptions from our previous study (Homagain et al. 2015). Within the biochar-based bioenergy production system boundary and study assumptions, we found that pyrolysis process accounts for the highest share of $36 \%$ cost in the production system; whereas land application accounts for $14 \%$, feedstock collection for $12 \%$, and transportation cost for $9 \%$ of the total production cost. Land application scenarios are economically viable with 12 to 13 years of break-even time, when carbon sequestration is credited for at least CAD 60 per tonne of $\mathrm{CO}_{2} \mathrm{e}$. Therefore, if biochar and bioenergy are co- produced, these can not only provide an economic alternative to fossil fuel energy production, but also help in sequestering stable carbon for longer periods of time. However, utilization of forest biomass may warrant an improvement in the regional biomass harvesting policy.

\section{Endnotes}

${ }^{1}$ Biochar is a highly porous and stable carbon-rich co-product of pyrolysis that has many uses including soil amendments and long term carbon sequestration. Although chemically similar, biochar differs from charcoal in the sense that it is not used as fuel (Lehmann and Joseph 2009).

${ }^{2}$ Pyrolysis is defined as a thermochemical decomposition process occurring in the absence of oxygen (Spokas et al. 2012). In this paper we deal with biochar produced from woody biomass in a bioenergy plant using the slow pyrolysis technique, a process that maximizes production, at $300-500{ }^{\circ} \mathrm{C}$ with a vapour residence time of $5-30 \mathrm{~min}$ (Please see details in Homagain et al. 2015).

${ }^{3}$ Bioenergy is the energy derived from the conversion of biomass where biomass may be used directly as fuel, or processed into liquids and gases.

${ }^{4} \mathrm{~A}$ carbon credit (often called a carbon offset) is a financial instrument that represents a tonne of $\mathrm{CO}_{2}$ (carbon dioxide) or $\mathrm{CO}_{2} \mathrm{e}$ (carbon dioxide equivalent gases) removed or reduced from the atmosphere from an emission reduction project, which can be used, by governments, industry or private individuals to offset damaging carbon emissions that they are generating.

\section{Additional file}

Additional file 1: Life Cycle Cost Assessment (LCCA). (XLSX 735 kb)

\section{Abbreviations}

AAFC: Agriculture and Agri Foods Canada, a federal department;

AGS: Atikokan Generating Station. A 200 MWh power generating station owned by OPG. This is the largest wood pellet burning station in North America as of 2014 when it was converted from lignite coal burning to wood pellets; C: Carbon; CAD: Canadian dollar; CCS: Carbon capture and storage; CEC: California Energy Commission; $\mathrm{CO}_{2}$ : Carbon dioxide;

$\mathrm{CO}_{2} \mathrm{e}$ : Carbon dioxide equivalent, is a standard unit for measuring carbon footprints to express the impact of each different greenhouse gas in terms of the amount of $\mathrm{CO}_{2}$ that would create the same amount of warming. Carbon footprints of different greenhouse gases can be expressed as a single number as $\mathrm{CO}_{2} \mathrm{e}_{\text {; }} \mathrm{EIOLCA}^{\oplus}$ : Environmental Input and Output Life Cycle Assessment, a software developed by GDI; FCC: Feedstock collection cost; GDI: Green Design Institute. Developer of EIOLCA; GHG: Greenhouse Gas; IBI: International Biochar Initiative, USA; IEA: International Energy Agency, an autonomous intergovernmental organization established in the framework of the Organisation for Economic Co-operation and Development (OECD) in 1974 in the wake of the 1973 oil crisis; IRENA: International Renewable Energy Agency; LAC: Land application cost; LCC: Total life cycle cost; LCCA: Life cycle cost assessment; MNRF: Ministry of Natural Resources and Forestry, Ontario, Canada; MOECC: Ministry of Environment and Climate Change, Ontario, Canada; MSC: Machine and setup cost; MWh: Megawatt hour; NPV: Net Present Value. It is the difference between the present value of total revenue (cash inflows) and the present value of total cost (cash outflows) discounted for the entire investment period; NREL: National 
Renewable Energy Laboratory of USA; NWO: Northwestern Ontario. A big section of Province of Ontario covering about 52 million ha area; OPG: Ontario Power Generation, a crown corporation owned by Province of Ontario; PC: Pyrolysis cost; Pers. Comm.: Personal communication; ROI: Return on investment. It is the most common profitability ratio of a project which is usually expressed as a percentage of net profit and is typically used for financial decisions, to compare the efficiency of different investments; SimaPro: : A LCA software developed by Pre Consultants, the Netherlands; SPC: Storage and processing cost; TC: Transportation cost; WPAC: Wood Pellet Association of Canada

\section{Acknowledgements}

Financial contributions from (1) Natural Sciences and Engineering Research Council of Canada through Industrial Postgraduate Scholarships (NSERC-IPS), (2) Ontario Graduate Scholarship (OGS) and (3) Ontario Power Generation $(\mathrm{OPG})$ for this study are highly acknowledged.

\section{Authors' contributions}

$\mathrm{KH}$ as a first author conducted all analyses, interpreted results and wrote and revised the manuscript. CS as a principal supervisor and NL \& MS as academic committee members made substantial contributions to the layout and design of the study and interpretation of the results. All authors read and approved the final manuscript.

\section{Authors' information}

$\mathrm{KH}$ is a recent PhD graduate from Faculty of Natural Resources Management of the Lakehead University and currently working with Ontario Ministry of Natural Resources and Forestry (MNRF) as a Regional Analyst. CS (Socio economist) and NL (Ecologist) are both Professors at Lakehead University with multi-disciplinary forestry-ecology-economics and statistics background. MS is a Forest Growth and productivity research scientist in Ontario Forest Research Institute of MNRF.

\section{Competing interests}

The authors declare that they have no competing interests.

\section{Author details}

${ }^{1}$ Faculty of Natural Resources Management, Lakehead University, 955 Oliver Rd., Thunder Bay, ON P7B 5E1, Canada. ${ }^{2}$ Ontario Forest Research Institute, 1235 Queen Street E, Sault Ste. Marie, ON P6A 2E5, Canada.

Received: 31 May 2016 Accepted: 26 August 2016

Published online: 14 September 2016

\section{References}

AAFC Agriculture and Agri Food Canada (2008) Analysis of the logistical costs associated with second generation biofuel feedstocks modelled supply chain logistical costs associated with cellulosic ethanol production in Canada. http://www.agr.gc.ca/eng/about-us/publications/economic-publications/ alphabetical-listing/analysis-of-the-logisticalcosts-associated-with-secondgeneration-biofuel-feedstocks-modelled-supply-chain-logistical-costsassociatedwith-cellulosic-ethanol-production-in-canada/?id=1247181726624

Alam MB, Pulkki R, Shahi C (2012) Woody biomass availability for bioenergy production using forest depletion spatial data in northwestern Ontario. Canadian Journal of Forest Research 42(3):506-516

Bank of Canada (2013) Selected historical interest rates for Canada. http://www. bankofcanada.ca/rates/interestrates/selected-historical-interest-rates/

Bruun EW, Muller-Stover D, Ambus P, Hauggaard-Nielsen H (2011) Application of biochar to soil and N2O emissions: potential effects of blending fast-pyrolysis biochar with anaerobically digested slurry. Eur J Soil Sci 62:581-589

Cleary J, Wolf DP, Caspersen JP (2015) Comparing the life cycle costs of using harvest residue as feedstock for small- and large-scale bioenergy systems (part II). Energy 86:539-547

Coleman M, Page-Dumroese D, Archuleta J, Badger B, Chung W, Venn T, Loeffler D, Jones G, and McElligott K (2010) Can Portable Pyrolysis Units Make Biomass Utilization Affordable While Using Bio-Char to Enhance Soil Productivity and Sequester Carbon? USDA Forest Service Proceedings RMRS-P-61. 2010

EPA Environment Protection Agency (2010) Guidelines for Preparing Economic Analyses. Environment Protection Agency USA. https://www.epa.gov/ environmental-economics/guidelines-preparing-economic-analyses
Galinato SP, Yoder JK, Granatstein D (2011) The economic value of biochar in crop production and carbon sequestration. Energy Policy 39:6344-6350

Gautam S, Pulkki R, Shahi C, Leitch M (2010) Economic and energy efficiency of salvaging biomass from wildfire burnt areas for bioenergy production in northwestern Ontario: A case study. Biomass \& Bioenergy 34:1562-1572

GDI Green Development Institute (2010) Environmental input output life cycle assessment. http://www.eiolca.net/

Hacatoglu K, James McLellan P, Layzell DB (2011) Feasibility study of a Great Lakes bioenergy system. Bioresource Technology 102(2):1087-1094

Homagain K, Shahi C, Luckai N, Sharma M (2015) Life cycle environmental impact assessment of biochar-based bioenergy production and utilization in Northwestern Ontario, Canada. J For Res 26:799-809

IBI International Biochar Initiative (2016) Biochar research and educational resources. http://www.biocharinternational.org/research/education [Accessed 10 Dec 2015]

IEA International Energy Agency (2015) World Energy outlook 2015: Executive summary. Paris, France

IRENA International Renewable Energy Agency (2012) Renewable Energy Technologies: Cost Analysis Series. Biomass for power generation Volume 1. https://www.irena.org/DocumentDownloads/Publications/RE_Technologies_ Cost_Analysis-BIOMASS.pdf

Kaliyan N, Morey RV, Tiffany DG (2015) Economic and environmental analysis for corn stover and switchgrass supply logistics. Bioenergy Res 8:1433-1448

Kennedy M, Wong R, Vandenbroek A, Lovekin D, Raynolds M (2011) Biomass Sustainability Analysis. An assessment of Ontario-sourced forest-based biomass for electricity generation. FINAL REPORT. Revision C. Pembina Institute, Alberta

Klinar D (2016) Universal model of slow pyrolysis technology producing biochar and heat from standard biomass needed for the techno-economic assessment. Bioresour Technol 206:112-120

Kulyk N (2012) Cost-benefit analysis of the biochar application in the U.S. Cereal Crop Cultivation. Technical Report \# 12. Center for Public Policy and Administration University of Massachusetts, Amherst

Kung CC, Mccarl BA, Cao XY (2013) Economics of pyrolysis-based energy production and biochar utilization: A case study in Taiwan. Energy Policy 60:317-323

Lehmann J, Joseph S (2009) Biochar for environmental management: An introduction. In: Lehmann J, Joseph S (eds) Biochar for environmental management science and technology. Earthscan, London, Washington D.C., pp 1-12

Lyman R (2015) Climate change targets for Canada examining the implications. The Road to Paris_Climate Change Talks December 2015. http:// friendsofscience.org/assets/documents/climate_change_implications_Lyman. pdf. Accessed 31 May 2016

Major J, Rondon M, Molina D, Riha SJ, Lehmann J (2010) Maize yield and nutrition during $4 \hat{A}$ years after biochar application to a Colombian savanna oxisol. Plant and Soil 333(1-2):117-128

McCarl BA, Peacoke C, Chrisman R, Kung C-C, Sands RD (2009) Economics of biochar production, utilization and greenhouse gas offsets. In: Lehmann J, Joseph S (eds) Biochar for environmental management science and technology. Earthscan, London, Washington D.C., pp 341-358

McElligott K, Page-Dumroese D, Coleman M (2011) Bioenergy production systems and biochar application in forests: potential for renewable energy, soil enhancement, and carbon sequestration. RN-46. USDA Rocky Mountain Research Station, Fort Collins, pp 1-14

MNRF Ontario Ministry of Natural Resources and Forestry (2015) Forest management units in Ontario. Ontario Ministry of Natural Resources and Forestry. http://www.efmp.Irc.gov.on.ca/eFMP/home.do

MOECC Ontario Ministry of Environment and Climate Change (2015) Ontario carbon target news release. Ontario ministry of environment and climate change. https://news.ontario.ca/ene/en/2015/05/ontario-first-provinceincanada-to-set-2030-greenhouse-gas-pollution-reduction-target.html

NREL National Renewal Energy Laboratory (2010) Techno-Economic Analysis of Biomass Fast Pyrolysis to Transportation Fuels. National Renewal Energy Laboratory of the United States. Technical Report NREL/TP-6A20-46586 November 2010. p73.

OPG Ontario Power Generation (2012) Atikokan Generating Station bio-mass fuel suppliers announced: meeting the needs of a growing economy in Northwestern Ontario. http://www.opg.com/news/releases/ 121122Atikokan\%20Fuel\%20Contracts_FINAL.pdf [Assessed 13 July 2014]

Patel M, Zhang XL, Kumar A (2016) Techno-economic and life cycle assessment on lignocellulosic biomass thermochemical conversion technologies: A review. Renewable Sustainable Energy Rev 53:1486-1499 
PowerMax (2015) 1000kw Biomass pyrolysis/gasification system technical specification. http://powermax1234.en.ec21.com/Biomass_Gasifier_Power_ Plant-7762130_7762661.html

Pratt K, Moran D (2010) Evaluating the cost-effectiveness of global biochar mitigation potential. Biomass Bioenergy 34:1149-1158

PRé Consultants (2013) SimaPro Software for life cycle assessment. www.presustainability.com/software. Accessed May 2014

Roberts KG, Gloy BA, Joseph S, Scott NR, Lehmann J (2010) Life cycle assessment of biochar systems: Estimating the energetic, economic, and climate change potential. Environ Sci Technol 44:827-833

Rogers JG, Brammer JG (2012) Estimation of the production cost of fast pyrolysis bio-oil. Biomass Bioenergy 36:208-217

Ronsse F, van Hecke S, Dickinson D, Prins W (2013) Production and characterization of slow pyrolysis biochar: influence of feedstock type and pyrolysis conditions. GCB Bioenergy 5:104-115

Shackley S, Hammond J, Gaunt J, Ibarrola R (2011) The feasibility and costs of biochar deployment in the UK. Carbon Manage 2:335-356

Simon D, Tyner WE, Jacquet F (2010) Economic analysis of the potential of cellulosic biomass available in France from agricultural residue and energy crops. Bioenergy Res 3:183-193

Sohi SP (2013) Pyrolysis bioenergy with biochar production-greater carbon abatement and benefits to soil. GCB Bioenergy 5:-i-iii

Spokas KA, Cantrell KB, Novak JM, Archer DW, Ippolito JA, Collins HP, Boateng AA, Lima IM, Lamb MC, McAloon AJ, Lentz RD, Nichols KA (2012) Biochar: A synthesis of its agronomic impact beyond carbon sequestration. J Environ Qual 41:973-989

Upadhyay TP, Shahi C, Leitch M, Pulkki R (2012) Economic feasibility of biomass gasification for power generation in three selected communities of northwestern Ontario, Canada. Energy Policy 44:235-244

Winsley P (2007) Biochar and bioenergy production for climate change mitigation. NZ Sci Rev 64:5-10

Wood SM, Layzell DB (2003) A Canadian Biomass Inventory: Feedstocks for a Bio-based Economy. BIOCAP Canada Foundation, Queen's University Ontario, Canada

Woolf D, Amonette JE, Street-Perrott FA, Lehmann J, Joseph S (2010) Sustainable biochar to mitigate global climate change. Nat Commun 1:56

WPAC Wood pellet association of Canada (2013) Canadian Wood Pellet production outlook 2013. Wood pellet association of Canada. http://www. pellet.org/about/publications

Yoder J, Galinato S, Granatstein D, Garcia-Prez M (2011) Economic tradeoff between biochar and bio-oil production via pyrolysis. Biomass Bioenergy 35:1851-1862

Zhang Y (2010) Life cycle environmental and cost evaluation of bioenergy systems. University of Toronto, Dissertation

\section{Submit your manuscript to a SpringerOpen ${ }^{\circ}$ journal and benefit from:}

- Convenient online submission

- Rigorous peer review

- Immediate publication on acceptance

- Open access: articles freely available online

- High visibility within the field

- Retaining the copyright to your article

Submit your next manuscript at $\gg$ springeropen.com 